\title{
Knowledge Mapping of Ethnic Identity and Acculturation Based on the Method of Bibliometric
}

\author{
Yuan Shuangyun and Li Hongxia ${ }^{1}$ \\ Rattanakosin International College of Creative Entrepreneurship, Rajamangala University of \\ Technology Rattanakosin, Thailand
}

\begin{abstract}
Ethnic identity and acculturation is a multidisciplinary research field. It is not easy for researchers to gain a panoramic view of the knowledge structure in this field. The bibliometric of knowledge mapping provides researchers with a scientific quantitative research method of statistics, description, and prediction of academic status and development trends. The purpose of this study is to help researchers understand the critical knowledge, evolution trend, and research frontier of the current research. Using bibliometrics software Citespace and Bicomb, this study analyzed 1557 bibliographic data in the Web of Science database and found that: 1)the research field development has gone through three stages, and we knew some representative critical scholars and key literature; 2) The literature knowledge mapping co-citation and the co-occurrence of keywords showed the research hot spots; 3) The results of burst detection and central node analysis reveal the research frontier and development trend. The globalization of the world economy has led to the rapid expansion of research objects from immigrants in the United States to the whole world. Meanwhile, there are still many disputes about theoretical models, constructs, and structural dimensions in the research field, which are the directions that future researchers need to study further.
\end{abstract}

Keywords: acculturation, bibliometric analysis, ethnic identity, knowledge mapping.

\section{Introduction}

Ethnic groups have two main dimensions of ethnic identity and acculturation (Laroche et al.,1997). Ethnic identity refers to a sense of belonging informed by clear knowledge of one's roots, history, and culture, a positive attitude toward the group, and involvement in cultural practices (Halpern, 2018; Soyer, 2019; Teppang, Han, and Lee, 2019). It derives from a sense of peoplehood within a group, a culture, and a particular setting (Phinney, 2007). Acculturation refers to the process of cultural and psychological changes caused by direct and continuous contact between two or more groups with different cultures and their members, which may be caused by a specific group and its members or the two parties in contact (Berry,1989; Bigagli, 2019). Ethnic identity can be considered as an aspect of the process of acculturation, which differs from other aspects in that it focuses on the subjective feeling of a person's ethnic (Gurer, 2019; Phinney, 2003). Acculturation and ethnic identity are two independents but closely related research fields. When studying the acculturation of ethnic groups, we have to consider

${ }^{1}$ Corresponding author; lihongxia@ctbu.edu.cn 
the problem of ethnic identity. This paper takes it as the research field of Ethnic Identity and Acculturation (EIA).

EIA researches are multidisciplinary across areas, with researchers from their respective knowledge backgrounds with different problem consciousness and theory of caring. It is not easy for researchers in the EIA field to gain a panoramic view of the knowledge structure, evolution, and key nodes. Before the advent of bibliometrics, researchers who wanted to quickly obtain a panoramic view of a discipline or research field mainly relied on peer-reviewed articles or anthologies. One of the apparent limitations of this method is that it is subject to the knowledge vision and subjective judgment of peers, and in many cases, it cannot fully reveal the critical literature and emerging research hotspots, and it is easy to cause controversy (Peng, Zhu, \& Wu, 2020; Ratini, 2019). The appearance of bibliometric analysis tools provides another possibility for researchers, that is, from pure subjective judgment to the combination of subjective judgment and objective measurement.

Bibliometrics is a quantitative analysis method, which uses mathematical and statistical methods to describe, evaluate, and predict the current situation and development trends of science and technology (Huang et al., 2020). Citespace and Bicomb are currently the most commonly used bibliometric analysis software in China. Among them, Citespace is a visualization software based on co-citation analysis theory and clustering algorithm, conducts quantitative analysis on the literature in specific research fields, and uses a series of visualization mapping to achieve the potential dynamic mechanism of domain evolution analysis and exploration of the frontier of domain development (Chen, C., \& Leydesdorff, 2014).

The application of Citespace is mainly in the fields of Library and Information Science, Medical, and Economics (Tao et al., 2020; Wu, Wang, Yan, \& Zhao, 2020); there are few significant studies in the EIA research field. This paper attempts to outline the knowledge structure in the EIA field by using bibliometric analysis methodology. However, this method also has limitations; that is, it relies on the relevant bibliographic database. If the coverage of the bibliographic database is insufficient or the quality is poor, it may directly affect the quality of the subsequent metrological analysis.

\section{Data Sources and Research Methodology}

In this study, we used the Web of Science (WOS) as the data source. WOS integrates Science Citation Index (SCI), Social Sciences Citation Index (SSCI), Art \& Humanities Citation Index (A\&HCI), and Conference Proceedings Citation Index-Social Sciences \& Humanities (CPCI-SSH). It is currently the world's most profound and most complete database providing Citation Index data. Unlike EBSCO, Springer, Wiley-Blackwell, and other large databases, the WOS database covers all source journals of SSCI, and its sub-databases enjoy high authority in the academic world. The retrieval method of this data collection was "Topic = ethnic identity AND acculturation." After searching the four databases of WOS (SSCI, A\&HCI, CPCI-SSH, SCI), we obtained 1574 pieces of relevant literature index data. Then we purified the obtained data by three standards of the general article, proceedings paper and review, and obtained 1559 bibliographic data. Finally, we preprocessed the obtained data with the data deduplication function of Citespace and obtained 1557 target bibliographic data. The data collection timeframe was from 1990 to 2020 (the database's data collection time is 1990). The retrieval date is May 9, 2020.

CiteSpace and Bicomb are commonly used bibliometric analysis software by Chinese scholars. In this paper, we used Bicomb for statistical analysis of the year, author, institution, country, keywords of the literature, synonym keyword combination processing, statistics highfrequency keyword, generation word matrix, and co-occurrence matrix. We sorted out the key node literature through the use of visual software CiteSpace for the analysis of literature co- 
citation, drew a knowledge map, and analyzed the evolution of research in the field by using the clustering algorithm and burst word detection functions to analyze research hotspots and research frontiers.

In this study, when using Citespace to generate knowledge mapping, if there is no particular explanation, the parameter thresholds are set according to the following steps: 1)import bibliographic data into Citespace software; 2)Set parameter values in the software to "TimeSlicing=1990-2020", "YearsPerSlice=4", "TermSource" by default, "TermType=BurstTerms," "Pruning=Minimum Spanning Tree," and "NodeType" to be flexibly selected as required by the research. Among them, 2020 in the data time range refers to the data limited to the data collection time range, that is, the data up to May 9, 2020.

\section{Literature Analysis}

\section{Annual Volume Analysis}

To some extent, the annual total distribution of the literature can reflect the research status of the field at a particular stage. Besides, the total number of papers published each year is also an important index to measure scientific research output. Using Bicomb to extract the year data from the bibliographic data, we analyzed the overall research trend in the EIA field and obtained the time trend chart of the number of literature (Figure 1).

According to the trend of publications, the development of the EIA research field mainly goes through three stages: 1) the initial stage; 2) the development stage; and 3) the rapid development stage. Before 1998, it was the initial research stage, and only a few or no papers were published annually. From 1998 to 2008 is the development stage. The number of articles published each year begins to grow slowly, from 15 in 1998 to 51 in 2008 . Since 2009 is the rapid development stage and the number of articles published each year shows an evident trend of rapid growth, from 79 in 2009 to 141 in 2019.

\section{Figure 1}

Distribution map of annual total literature in the EIA field

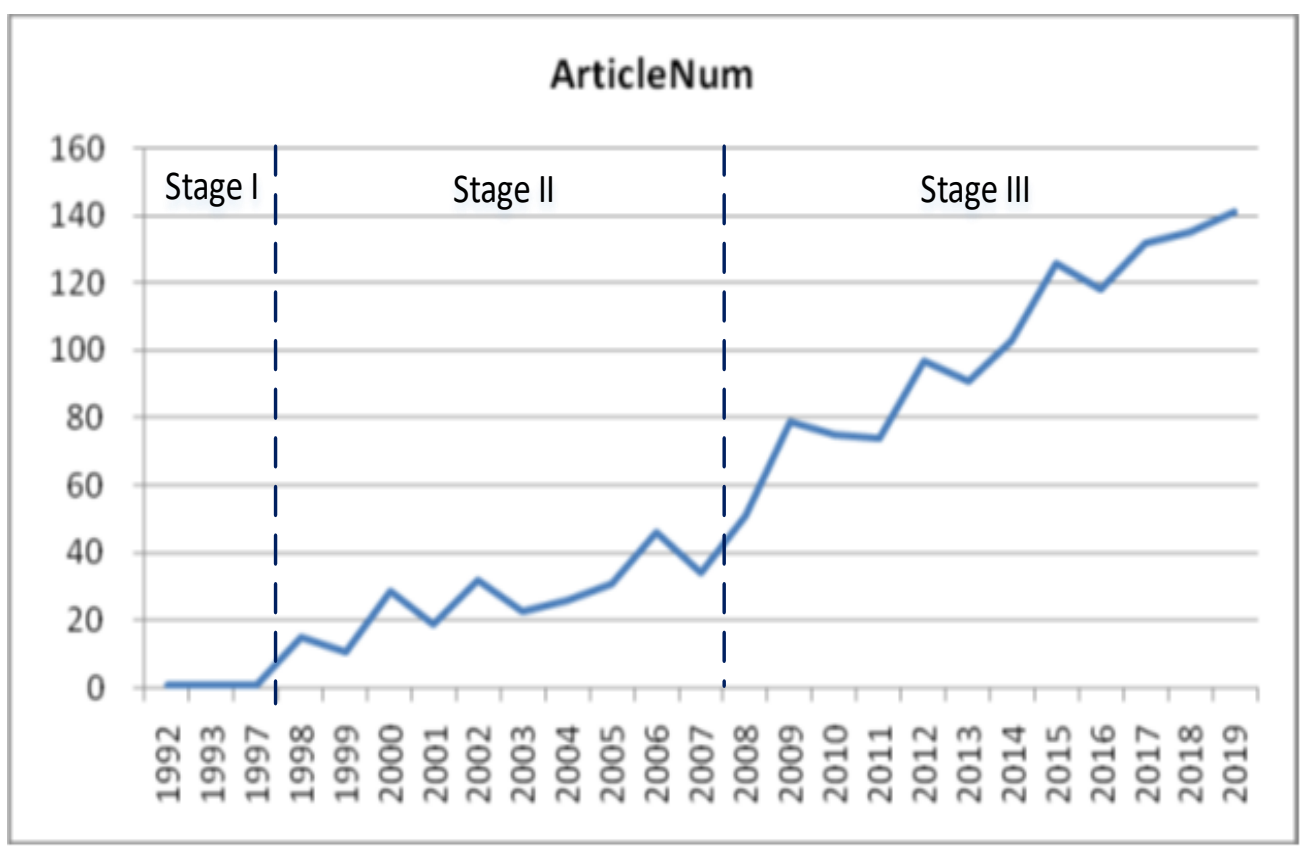




\section{Institutional and Country Analysis}

We extracted institutions data from Bicomb and listed the top ten institutions in the following Table 1. In these 10 institutions, seven are from the United States, two from the Netherlands and one from Australia. All of them are universities, and the top three are Arizona State Univ, Miami Univ, and Utrecht Univ.

Besides, according to the national data in the literature, the United States is the core country in the EIA research field, with 870 articles published, accounting for $55.9 \%$ of the total literature. Other countries at the top of the list are Canada (127), Netherlands (103), Australia (86), and Germany (79).

\section{Table 1}

\begin{tabular}{llllll}
\multicolumn{7}{l}{ TOP 10 institutions in the EIA field } & $(1990-2020)$ & \\
\hline SN & Institutions & ArticleNum & SN & Institutions & ArticleNum \\
\hline 1 & Arizona State Univ & 63 & 6 & Univ So Calif & 34 \\
2 & Univ Miami & 58 & 7 & Univ Texas Austin & 33 \\
3 & Univ Utrecht & 36 & 8 & Tilburg Univ & 29 \\
3 & Univ llinois & 36 & 9 & Univ Calif Los Angeles & 28 \\
5 & Univ Michigan & 34 & 10 & Univ Queensland & 27 \\
\hline
\end{tabular}

\section{Key Scholars Analysis}

Key scholars are leading the way in a field of research. The author's cited frequency can reveal the degree of attention paid to the author in the research field and serve as an indicator to measure his/her influence. According to the previous analysis, since 2009 is a rapid development stage, and the analysis of high-volume authors in this stage can help researchers find the most recent representative authors in the EIA field.

We extracted the citation author data and the author data (2009-2020) from Bicomb, counted the top 10 authors with high citation frequency (Table 2) and the top 10 authors with high publication numbers (Table 3).

According to Table 2, Berry, Phinney, and Schwartz were cited much more frequently than other scholars. These three scholars have the most substantial influence and are the key scholars in the EIA research field. Among them, John W. Berry is one of the founders of the International Association of Intercultural Psychology and the pioneer of intercultural psychology. His acculturation theory, known as "Berry's framework of bidimensional model acculturation theory", plays an important pioneering and foundational role in people's understanding and research of cross-cultural psychology. Phinney JS, a Dutch psychologist, is a pioneering scholar in the field of ethnic identity. He focuses on studying ethnic identity and its impact on psychology and establishes an operational theoretical framework for the study of ethnic identity psychology. After his theory, a large number of research results appeared based on this theory (Lewis, Raque-Bogdan, Lee, \& Rao, 2018; Y. J. Wu, Outley, \& MatarritaCascante, 2019). Schwartz SJ is another crucial figure in the field of cross-acculturation in the United States. Based on previous studies, he elaborated and distinguished some concepts of cross-acculturation and proposed concepts such as Acceptance Context and Biculturalism.

As Table 3shows, Schwartz, Unger, and Zamboanga are among the most prolific authors in recent years. As can be seen, Schwartz is one of the most influential and prolific authors in recent years. His latest signed article published in 2020 is "Dynamic Transition Patterns in Acculturation Among Hispanic Adolescents." This study investigated the transition patterns of acculturative processes within and across indicated domains in recent - immigrant Hispanic adolescents (Lee et al., 2020). Schwartz's latest research can be a primary focus of researchers, and to a certain extent, helpful for them to learn about the forefront knowledge of 
the EIA research field. The specific research frontiers and hotspots are presented in the following sections using Citespace software.

\section{Table 2}

TOP 10 authors cited in the EIA field (1990-2020)

\begin{tabular}{llllll}
\hline SN & Cited Author & Citation frequency & SN & Cited Author & Citation frequency \\
\hline 1 & Berry, JW & 2344 & 6 & Tajfel H. & 344 \\
2 & Phinney JS & 1832 & 7 & Ward C & 224 \\
3 & Schwartz, SJ & 716 & 8 & Birman D & 223 \\
4 & Verkuyten M & 387 & 9 & Benet - Martinez V & 216 \\
5 & Umana - Taylor AJ & 345 & 10 & Lafromboise T & 198 \\
\hline
\end{tabular}

\section{Table 3}

TOP 10 authors of published articles in the EIA field (2009-2020)

\begin{tabular}{llllll}
\hline SN & The Author & ArticleNum & SN & The Author & ArticleNum \\
\hline 1 & Schwartz, SJ & 35 & 6 & Lorenzo - Blanco EI & 16 \\
2 & Unger JB & 25 & 7 & Grim DW & 14 \\
3 & Zamboanga BL & 21 & 8 & Szapocznik J & 13 \\
4 & Van DE Vijver FJR & 20 & 9 & Verkuyten M & 13 \\
5 & Baezconde - Garbanati L & 16 & 10 & Jose Szapocznik & 12 \\
\hline
\end{tabular}

\section{Analysis of Highly Cited Literature}

Highly cited papers reflect the degree and focus of academic attention to research work. In the present research evaluation, citation frequency is an index to measure the importance of papers. In this paper, we extracted the citation data from Bicomb, and obtained the top 10 papers with the highest citation frequency, as shown in Table 4.

Berry is the author of three articles in Table 4. These articles are Berry's interpretation and application of his acculturation theory. In "Immigration, Acculturation, and Adaptation" (Berry, 1997), Berry elaborated on his acculturation theory framework, which is the most widely used theory of acculturation by far.

Articles ranked 2, 3, 4, and 10 in the table are Phinney's interpretation and application of ethnic identity theory. The measuring scale he developed in "The Multigroup Ethnic Identity Measure" is currently the most widely cited Ethnic Identity measurement scale, which can be applied to different groups. Based on this article, the author published another article, "Conceptualization, and Measurement of Ethnic Identity: Current Status and Future Directions" in 2007. In this paper, the author elaborated on the concept and structure of ethnic identity and proposed a revised scale for its measurement. After testing, the new scale has higher universality.

Lafromboise (1993) presented a hypothetical model outlining the dimensions of bicultural competence and emphasized the alternating pattern. In this model, it is assumed that a person can gain ability in two cultures without losing his or her cultural identity, or has to choose one culture over the other.

Schwartz, Unger, Zamboanga, and Szapocznik (2010) present an expanded acculturation model among international migrants and their immediate descendants. They proposed an operational definition for the context of reception and called for studies on the role that context of reception plays in the acculturation process.

Ryder, Alden, and Paulhus (2000) tested the one-dimensional (monolinear) model and two-dimensional(bilinear) model of acculturation through five different sample data, and the 
results showed that the bidimensional model is a more valid and useful operationalization of acculturation.

\section{Table 4}

\begin{tabular}{llc}
\multicolumn{1}{c}{ TOP 10 literature with the highest citation frequency in the EIA field (1990-2020) } \\
\hline SN & \multicolumn{1}{c}{ Citation } & Citation frequency \\
\hline 1 & Berry JW, 1997, APPL psychol-int REV, V46, P5 & 445 \\
2 & Phinney JS, 1990, PSYCHOL BULL, V108, P499 & 329 \\
3 & Phinney JS, 1992, J ADOLESCENT RES, V7, P156 & 309 \\
4 & Phinney JS, 2001, J SOC ISSUES, V57, P493 & 239 \\
5 & Lafromboise T, 1993, PSYCHOL BULL, V114, P395 & 198 \\
6 & Berry JW, 2006, APPL psychol-int REV, V55, P303 & 175 \\
7 & Berry j. w., 1980, ACCULTURATION THEORY, P9 & 171 \\
8 & Ryder AG, 2000, J PERS SOC PSYCHOL, V79, P49 & 170 \\
9 & Schwartz SJ, 2010, AM PSYCHOL, V65, P237 & 160 \\
10 & Phinney JS, 2007, J COUNS PSYCHOL, V54, P271 & 153 \\
\hline
\end{tabular}

\section{Analysis of Research Hotspots}

It is helpful for researchers to understand the latest research trends and find research problems by analyzing the hotspots and frontiers in the near stage. According to the previous development stage, we selected bibliographic data from 2009 to 2019 as the source data for hot spot and frontier analysis (the data of 2020, which is less than a full year is not included in the analysis scope).

Document co-citation analysis (DCA) can be used to identify key literature and research frontiers in a research area (Chen, C., Ibekwe-SanJuan, F., \& Hou, J., 2010). The co-citation refers to the phenomenon that the same article cites two articles. Generally, the frequency of co-citation may change with the increase of time, so the literature network formed based on the co-citation relationship is a dynamic structure. Co-citation analysis has the function of dynamic analysis and is suitable for analyzing the evolution of knowledge in a discipline or research field (Zeng Zhishen, 2008).

In Citespace, "TimeSlicing=2009-2019", "Node type=Reference," "Top=20," were set to obtain the visual knowledge map of literature co-cited (Figure 2).In the figure, there are 113 nodes, 141 link lines, density 0.0223 , Modularity $=0.6974$ ( $Q$ value, generally regarded as significant clustering structure of $\mathrm{Q}>0.3$ ), Silhouette $=0.6035$ ( $\mathrm{S}$ value, generally regarded as reasonable clustering of $S>0.5$ ). The nodes in the figure are annual rings. The larger the nodes are, the higher the overall frequency of the co-cited literature is. In the annual rings, blue represents the earlier years, and red represents the most recent years. The deep red in the center of the annual rings represents that the cited documents with the words are burst documents, and the thickness of the annual rings is in direct proportion to the frequency of the co-cited documents in that year. Some of the rings have a purple outer ring, indicating that the co-cited literature has a significant degree of centrality. The connection between co-cited references means that two co-cited references often appear in the same article. The thicker the connection is, the higher the co-occurrence frequency is.

Cluster analysis refers to grouping a collection of physical or abstract objects into multiple classes composed of similar objects using clustering algorithms (Chen, C., \& Leydesdorff, 2014). Cluster analysis is based on the similarity of analysis objects, and the Loglikelihood ratio (LLR) algorithm was used in this paper. Hotspot clustering analysis is a natural advantage for the clustering of co-induced networks based on connection relationship rather than node attributes. It can cluster the sample space of any shape and converge to the optimal global solution. Among them, Q value and S value are two crucial measurement indexes about the network's overall structure. Keyword phrases are extracted from the titles of specific clusters as cluster tags to characterize and identify clusters. From the aggregated Figure 2, we can see 
that the research hotspots in this field mainly form eight aspects, which are as follows: Academic trajectories, \#1 Longitudinal analysis, \#2 Family functioning, \#3 Sociocultural adaptation, \#4 Dual identity development, \#5 refugee adolescent, \#6 Negative contact experience, \# 7 Korean American. The key articles in each cluster block are the nodes shown in Figure 2.

\section{Figure 2}

Cluster map of co-cited articles in the EIA field (2009-2019)

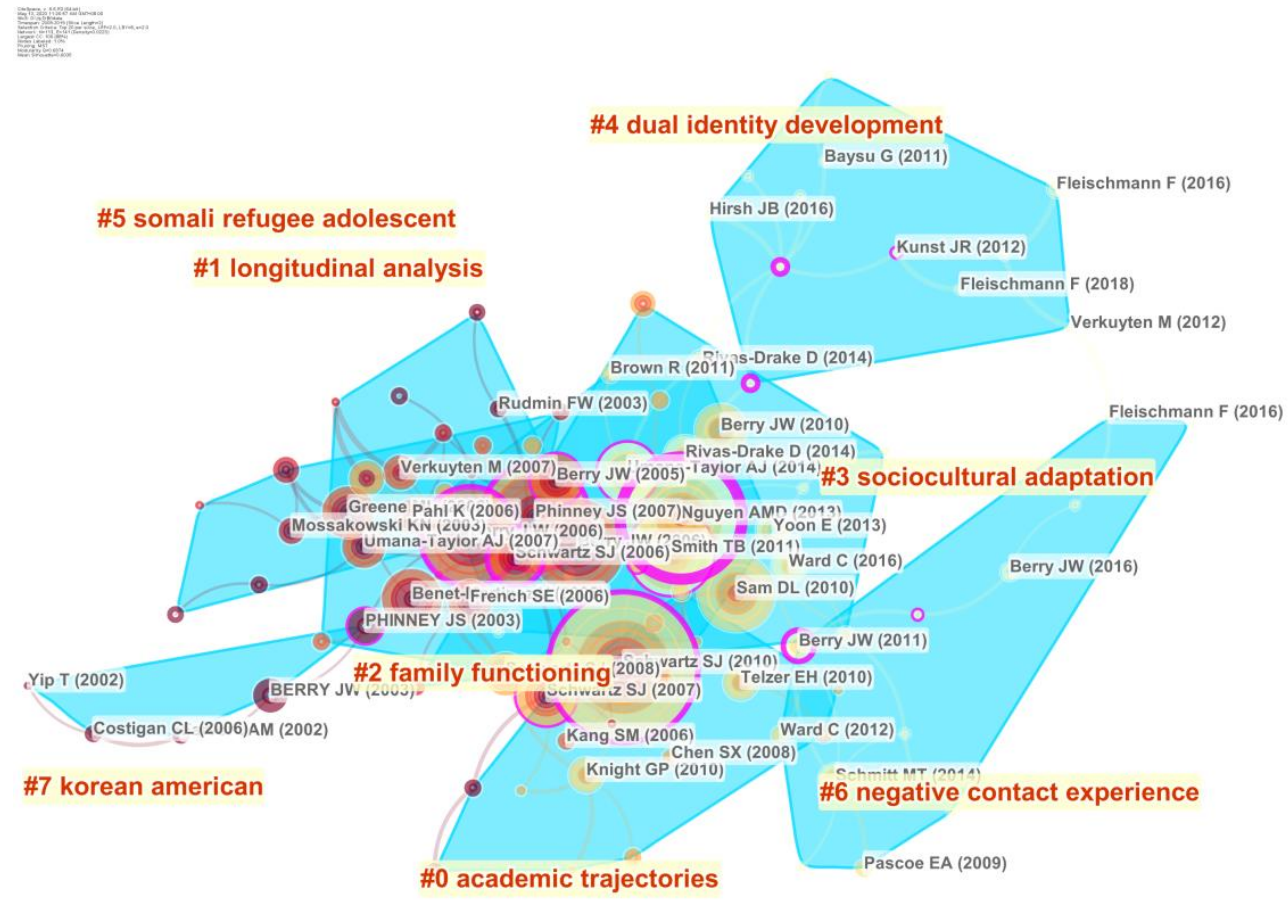

Keyword co-occurrence is another method to detect research hotspots. Using Bicomb to generate keyword co-occurrence matrix and construct keyword co-occurrence networks can identify research hotspots in the field. Extract the keyword list of co-occurrence frequency TOP 30 for display (Table 5).

\section{Table 5}

TOP 30 keywords of co-occurrence frequency (2009-2019)

\begin{tabular}{llllll}
\hline SN & The keyword & Frequency & SN & The keyword & Frequency \\
\hline 1 & acculturation & 771 & 16 & identification & 83 \\
2 & Ethnic identity & 540 & 17 & Perceived discriminatin & 79 \\
3 & identity & 244 & 18 & The health & 76 \\
4 & adolescents & 242 & 19 & youth & 72 \\
5 & immigrant & 178 & 20 & Asian American & 71 \\
6 & discrimination & 155 & 21 & assimilation & 68 \\
7 & Getting the health & 140 & 22 & Substitutes American & 66 \\
8 & adaptation & 127 & 23 & stress & 65 \\
9 & adjustment & 120 & 24 & integration & 63 \\
10 & attitude & 117 & 25 & The children & 63 \\
11 & immigration & 113 & 26 & Latino & 61 \\
12 & culture & 100 & 27 & behaviors & 58 \\
13 & Self esteem & 91 & 28 & migration & 58 \\
14 & American & 87 & 29 & scale & 57 \\
15 & The model & 85 & 30 & depression & 54 \\
\hline
\end{tabular}


According to table 5, we can find that the research objects in the EIA research field are mainly adolescents, Asian American, African, Latino, and the research content mainly include discrimination, getting health, adaptation, adjustment, attitude, self-esteem, stress, and behaviors.

\section{Research Frontier Analysis}

Research frontier refers to "a group of burst dynamic concepts and potential research problems"(Chen, C., \& Leydesdorff, 2014). In CiteSpace, Kleinberg's Burst Detection Algorithm was used to identify those cited articles (burst items) that have aroused the academic community's close attention in a specific time, and they are marked with annual red rings inside the nodes (see Figure 2). The longer the reference surge of a node lasts, the thicker the red ring of the node. Burst literature contains two dimensions of burst value and burst time. The literature with high emergence value means that it has received particular attention in the corresponding time interval, representing the research frontier of the field to some extent. Burst time interval reflects the dynamic change of a discipline or research field frontier hotspot. To display the latest research frontier information, this paper extracted burst literature from the latest burst time (2019), and they are key articles that represent the frontiers of the EIA research field (Table 6).

According to the table, the recent burst article is mainly distributed in the clustering of \#2, \#3, \#4 and \#6. Therefore, family functioning, sociocultural adaptation, dual identity development, and negative contact experience are the latest frontiers in the field of research.

\section{Table 6}

Classification table of burst words (Burst time 2019)

\begin{tabular}{llll}
\hline \multicolumn{1}{c}{ The References } & \multicolumn{1}{c}{ Strength } & \multicolumn{1}{c}{ Burst time interval } & ClusterID \\
\hline Zhang SY,2018, J RES PERS, V74, P66 & 3.72 & $2019-2019$ & 4 \\
Schotte K,2018, J YOUTH ADOLESCENCE, V47, P16 & 3.42 & $2019-2019$ & 4 \\
Ward C, 2016, CURR OPIN PSYCHOL, V8, P98 & 6.341 & $2017-2019$ & 3 \\
Rivas-drake, 2014, CHILD DEV, V85, P77 & 4.9148 & $2017-2019$ & 2 \\
Schmitt MT, 2014, PSYCHOL BULL, V140, P921 & 6.341 & $2017-2019$ & 6 \\
Rivas-drake, 2014, CHILD DEV, V85, P40 & 9.5865 & $2017-2019$ & 2 \\
Yoon E, 2013, J COUNS PSYCHOL, V60, P15 & 7.4172 & $2017-2019$ & 2 \\
Motti-Stefanidi F, 2012, REALIZING POTENTIAL, V0, & 4.5598 & $2017-2019$ & 3 \\
P117 & 4.9813 & $2017-2019$ & 6 \\
Ward C, 2012, INT J INTERCULT REL, V36, P472 & 6.6991 & $2017-2019$ & 6 \\
Berry JW, 2011, INT J INTERCULT REL, V35, P658 & 4.9813 & $2017-2019$. & 2 \\
Brown R, 2011, ADV EXP SOC PSYCHOL, V44, P129 & 8.6723 & $2016-2019$ & 2 \\
Umana-Taylor AJ, 2014, CHILD DEV, V85, P21 & 8.7183 & $2016-2019$ & 3 \\
Sam DL, 2010, PERSPECT PSYCHOL SCI, V5, P472 & 9.4535 & $2015-2019$ & 3 \\
Berry JW, 2010, INT J INTERCULT REL, V34, P191 & 15.3087 & $2015-2019$ & 2 \\
Schwartz SJ, 2010, AM PSYCHOL, V65, P237 & 4.8693 & $2014-2019$ & 2 \\
Smith TB, 2011, J COUNS PSYCHOL, V58, P42 & & & 2 \\
\hline
\end{tabular}

\section{Analysis of the Evolution Path}

According to the centrality, we screened the key node literature and sorted out the evolution path of the EIA research. The timeline map of Citespace can clearly shows the evolution path of key nodes over time (Figure 3). 
According to Figure 3, we found that during the development stage from 1998 to 2008, the researches represented by Berry $(2005,2006)$, Phinney $(2003,2007)$, and Schwartz $(2006,2007)$ were the research hotspots in this stage. The research at this stage mainly focuses on conceptual interpretation and theoretical research.

From 2009 to 2019, field research has developed rapidly, forming key nodes represented by more scholars, such as Schwartz (2010,2012), Smith (2011), Nguyen (2013), Berry (2011,2017), and Zhang (2018). The research at this stage presents a diversified development trend, and the research topics include family functioning, sociocultural adaptation, dual identity development, negative contact experience.

\section{Figure 3}

Cluster diagram of literature co-citation time line in the EIA field

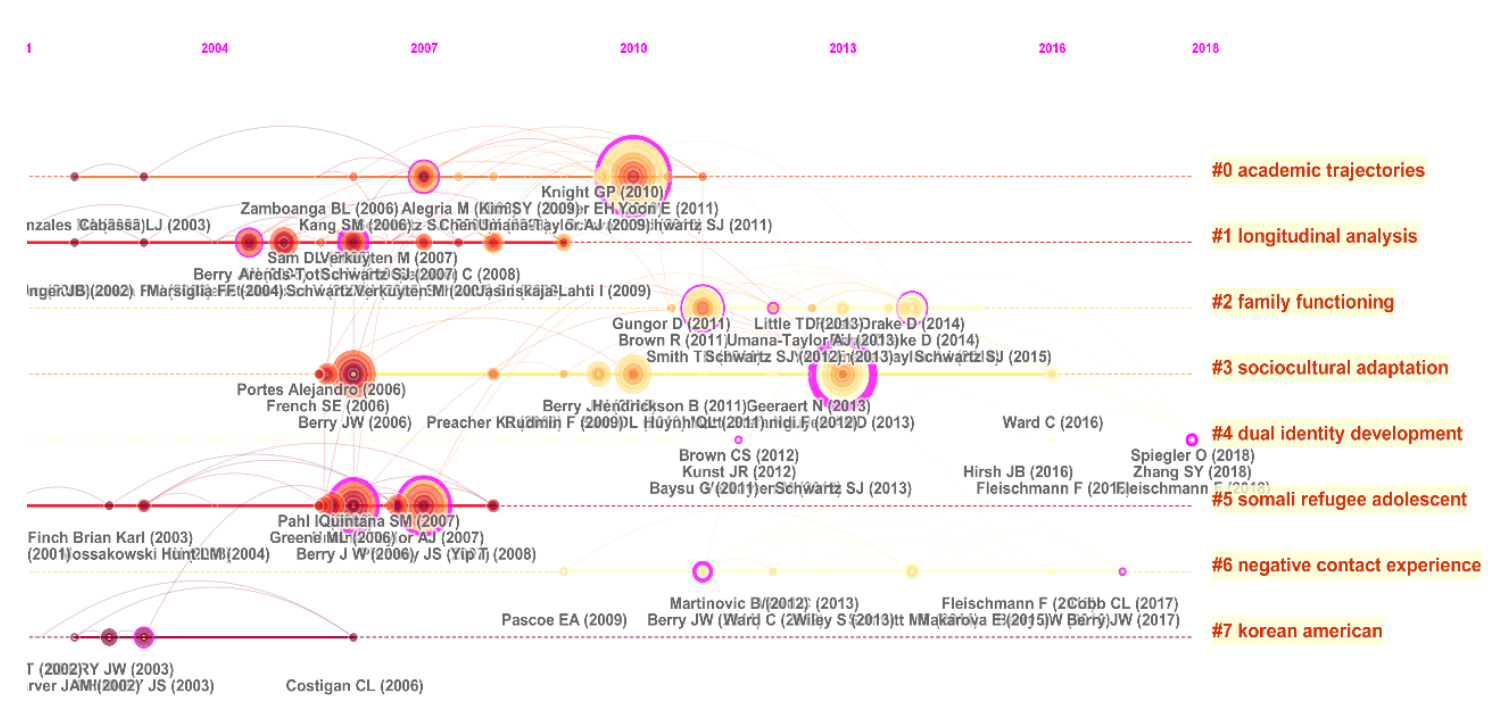

\section{Results and Discussions}

In this paper, we used the bibliometrics method to make a statistical analysis of the article's annual publication, research institutions, key authors, keywords, and citations. We used co-citation analysis, keyword co-occurrence analysis, clustering algorithm, and burst algorithm to detect research hotspots, research frontiers, and evolution trends in the EIA research field, to provide critical knowledge reference for researchers.

According to the trend of publications, the development of the EIA research field mainly went through three stages: the initial stage (before 1998), the development stage (1998-2008), and the rapid development stage (since 2009). From publishing institutions and national analysis, research institutions in the EIA field are universities, and most of them are from the United States. The United States is the core country of the research area, accounting for 55.9\% of the published articles, far more than other countries, which is related to the fact that the United States is the largest immigration country in the world.

According to the statistical results of authors and citation data, Berry, Phinney, and Schwartz are highly cited authors in the field. Schwartz, Unger, Zamboanga are highly productive authors in the recent stage. Based on statistics of citation data and knowledge mapping, scholars can access key articles and quickly master fundamental knowledge of the field. 
The detection results from the research hotspots and frontiers show that the main targets of the research field focused on adolescents, Asian American, African American, and Latino, and the research content mainly included discrimination, mental health, adaptation, attitude, self-esteem, stress, and behaviors. The results of detection indicated that Family Functioning, Sociocultural Adaptation, Dual Identity Development, and Negative Contact Experience are the latest research frontiers. The key nodes of the central selection showed the evolution path of the research development, which verified the previous analysis results and further revealed the research development trend, providing researchers with a clear panoramic view of the field.

The impact of acculturation on individuals and ethnic groups is multifaceted; that is the reason why there are so many research topics. However, individual mental health is one of the critical aspects, and the acculturation ability of different groups is a significant factor affecting mental health. It is also the driving factor for the development of acculturation and mental health in Europe and America.

According to the analysis of the above, we will further discuss in this paper, the research methods and the development trends of the EIA. At the same time, we make recommendations for future researchers.

\section{A Bibliometric Method Based on Knowledge Mapping}

This paper adopts a visual bibliometric analysis method based on Knowledge Mapping. Knowledge Mapping in bibliometrics is a graph that shows the relationship between the development process and the structure of knowledge by taking the knowledge domain as the object (Chen, C., \& Leydesdorff, 2014). It has the dual nature and characteristics of "graph" and "spectrum": it is not only a visual knowledge graph but also a serialized knowledge genealogy, showing many complex relationships among knowledge units or knowledge groups, such as network, structure, interaction, crossover, evolution or derivation.

In the internet era, scientific exchange and technological innovation have entered a faster and more efficient rhythm. Under this background, the visualization method can be used to display the econometric analysis results, which can show the research trend and context more clearly. Bibliometrics based on Knowledge Mapping is a new bibliometrics method. While the traditional bibliographic method is a simple statistical analysis of bibliographic information, this new method is the deep excavation of literature. It uses the deep learning method to identify the entities in the literature and the relationships between them and displays them in the form of a knowledge map. This new approach opens up more possibilities in knowledge research.

\section{EIA Research Trends}

\section{Theoretical Models Trends}

The theoretical models in the literature were mainly about the development of acculturation models, which has experienced the development from monolinear to bilinear. Meanwhile, new frame theories are continuously proposed. Among them, Ward (2016) proposed a new conceptual framework of acculturation called ecology, which has been cited the most.

Most of the traditional monolinear models were based on assimilation view with the experiences of early 20th-century European immigrants to the United States. The monolinear model assumed that non-mainstream individuals would gradually adapt to mainstream culture's values and customs over time. Although the monolinear model significantly contributed to the definition and measurement of acculturation, it had a vital weakness. Some researchers argued that the monolinear model could not clearly distinguish between individuals who are highly accepted or uninterested in both cultures, the former representing the binary culture, while the 
latter are mostly on the edge of the two cultures (Huynh, Benet-Martinez, \& Nguyen, 2018). After Berry's (1997) bilinear model was proposed, more and more scholars began to pay attention to and support the bilinear model (Meca et al., 2017).

The bilinear model has experienced theoretical development (1998-2008) and practical application (2009-2019) since it was proposed, consistent with the previous analysis of the development stage. The problem of bicultural status and bicultural identity combined with bilinear theory has become the hotspot and frontier of current research (Zhang, S. Y., Verkuyten, M., \& Weesie, J. ,2018; Ferrari et al., 2019). However, the bilinear model also had its disadvantages, and scholars began to develop new acculturation models. Thus, there is no "absolute best" acculturation model. Instead, researchers can choose the model that best matches the research topic and the research population, and there are bound to be more new models of adaptation in the future.

\section{Research Object Trends}

In the development stage of the EIA research field (1998-2008), the research objects were mainly Mexican Americans and African Americans. The United States is the largest immigrant country globally, and the acculturation caused by the growth of immigrants has always been a concern, which is also one of the reasons why the United States has become a core country in the research field. Immigrants from different countries and their different cultures come together; the differences between their cultures have a high impact on social psychology and individual psychology. Meanwhile, immigration also has a profound impact on the mainstream groups in the countries of entry.

With the social development trend of globalization, in the rapid development stage of the research field (2009-2019), the issue of acculturation has become a global issue. Therefore, the research object of this stage became very extensive. Initially, the study was still focused on immigrants to the United States, but the scope of immigrants was expanded to include Asian Americans and Latinos. Then, as the global economy grew, more people came to reside for a short time, scholars began to study these sojourners. Meanwhile, as the research progressed, researchers have found that acculturation is not only a problem of immigrants but also a problem of ethnic minorities who have lived for generations in contact with mainstream groups. Some scholars began to focus on and study ethnic minorities. It should be noted that the majority were teenagers and students among all the research objects, and the majority were urban residents. At present, there are still few scholars studying ethnic minority residents living in rural areas.

\section{Structural Dimension Changes}

Ethnic identity and acculturation are both multi-layered and multi-dimensional structures. These dimensions are often positively correlated (Lee, 2005), but the empirical evidence available is ambiguous as to the extent to which the different dimensions constitute an overall concept or different aspects that need to be considered separately. Berry and Phinney (2006) believed that ethnic identity is the degree to which an individual feels part of an ethnic group, while acculturation is the degree to which an individual adapts to a particular culture. Ethnic identity and acculturation use different definitions but usually use similar variables. According to Kwan and Sodowsky (1997), the structure of ethnic identity includes four dimensions: behavior, cognition, morality, and emotion. Birman \& Trickett (2001) believe that acculturation at the individual level mainly includes two aspects of behavior and identity. Behavioral acculturation includes learning the new culture and accepting the dominant part of the culture, such as language and the ability to integrate into the new culture. The identity 
reflects the degree of conformity with the values, ideologies, attitudes, or beliefs of the mainstream cultural groups. Phinney et al. (2001) point out that the distinction between ethnic identity construction and acculturation is unclear because both rely on the representation of similar linguistic domains, the perceived influence of reference groups, and adherence to cultural conventions and food preferences. Laroche et al. (1997) report that ethnic identity and acculturation constitute two dimensions of ethnic groups. The relationship between ethnic identity and acculturation is complicated, and the existing studies are insufficient to determine the relationship or structure between them, which is something that scholars need to study further.

\section{Suggestions for Future Research}

\section{Open and Global Cooperation}

The acceleration of globalization and the development of information technology provide more opportunities for academic exchanges and cooperation between different countries (regions). EIA studies are mainly in the United States. The research cooperation between authors is insufficient, knowledge flow is not smooth, and large-scale cooperation network has not been formed. Although the current COVID-19 epidemic has hindered the process of internationalization for some time, it will not affect the social development of internationalization. Moreover, consistent with the novel Coronavirus problem, ethnic identity and acculturation are common problems faced by many countries. In the face of racial and cultural conflicts, countries, institutions, scholars, and other forces should unite to promote collaborative research. Knowledge knows no borders. Only scientific research based on openness and cooperation can develop faster and better.

\section{Research Fusion}

EIA needs to seek new development opportunities in discipline fusion as an interdisciplinary subject of ethnology, sociology, and cross-cultural psychology. Firstly, the fusion of internal disciplinary theories, such as ethnology and psychology; Secondly, external fusion with other disciplines, such as economics and medicine, is becoming more and more prominent (Hunt, Kolind, \& Antin, 2018). On the research methods, traditional qualitative or quantitative methods can no longer meet the needs of the information society. The intersection of EIA and computer science and information science is also one way to promote the development of EIA in the direction of science, precision, and efficiency.

\section{Research Expansion}

Ethnic identity and acculturation are affected by many environmental factors. The development of computer network technology has built a virtual network social environment for human society. It is the multi-dimensional embodiment of the real society in cyberspace. In the online society, people are using social media more and more frequently in their communication. Social media's use dramatically expands people's space for social interaction and information sharing (Chung \& Koo, 2015). Social media has become an essential means for people to relieve various cultural shocks and acculturation pressures they suffer in the multicultural environment (Mitra \& Evansluong, 2019), and is a vital network environment variable that affects acculturation and ethnic identity. However, the current research is mainly in traditional real environment research. For the emerging network environment variables, research is very little. As a result, EIA's research needs to be extended to larger virtual and real social environments. 


\section{Conclusions and Limitations}

The globalization of society has brought many opportunities, but also a series of acculturation and identity problems. With the rapid development of globalization, these problems have become general problems all over the world. The EIA research field becomes a hot research field for scholars at present. The existing research has obtained abundant research results and generated several representative scholars and theoretical articles. However, the results of development analysis showed that the scope of research objects needs to be expanded, and there are many controversies on theoretical models, constructs, and structural dimensions of the EIA research field. There is still a lot of development space for further research. Future researchers need to base their research on collaboration, fusion, and expansion, and combine the social characteristics of globalization and informatization to enrich and improve EIA theory and research results.

Ethnic identity and acculturation research are multidisciplinary cross-domain; researchers can further expand their research on interdisciplinary subjects in the future. They can use the research methods, perspectives, and paths of different disciplines to enrich the research field so that the subjects, methods, and perspectives show a diversified trend of development.

Bibliometrics is a scientific and effective method for library and information science research, which is used for statistics, description, and prediction of academic status and development trends. However, the quantity and quality of scientific literature is undoubtedly a measure of the technology level. The research in this paper is based on the WOS database, and the research results are relatively objective and impartial. However, due to the database's limitations, the data is not comprehensive enough, and some databases do not support catalog download. Therefore, there may be some deviations in the research results. Future research can consider using data mining techniques to expand the scope of source data collection and improve the quantity and quality of the article.

Meanwhile, the determination of the future frontier is a forward-looking work. The literature represents the history, which contains part of the future trend, but it can never fully reflect the future. There are some inevitable defects in the research based on bibliometrics, and the research results in this paper may have some deviation from the real future.

\section{Acknowledgments}

The research was substantially supported by a project (19SKGH091) from the Chongqing Education Commission of China and project from the Open Fund of Research Centre of Enterprise Management. This study was also substantially supported by a project (2053002, 2018103) from Chongqing Technology and Business University of China.

\section{References}

Adrados, J. L. R. (1997). Acculturation: The broader view. Theoretical framework of the acculturation scales. Substance Use \& Misuse, 32(12-13), 1919-1924. doi:10.3109/10826089709035604

Berry, J. W. (2005). Acculturation: Living successfully in two cultures. International Journal of Intercultural Relations, 29(6), 697-712. doi:10.1016/j.ijintrel.2005.07.013

Berry, J. W., \& Colette Sabatier. (2011). Variations in the assessment of acculturation attitudes: Their relationships with psychological wellbeing. International Journal of Intercultural Relations, 35, 12-23. doi:10.1016/j.ijintrel.2011.02.002

Berry, J. W., \& Feng Hou. (2017). Acculturation, discrimination and wellbeing among second 
generation of immigrants in Canada. International Journal of Intercultural Relations, 61, 11-22. doi:10.1016/j.ijintrel.2017.08.003

Berry, J. W., \& Sabatier, c. (2010). Acculturation, discrimination, and adaptation among the second generation Of immigrant youth in Montreal and Paris. Interethnic Journal of Intercultural Relations, 34 (3), 191-207. doi: 10.1016 / j.i jintrel. 2009.11.007

Berry, J. W., Kim, U., Power, S., Young, M., \& Bujaki, M. (1989). Acculturation attitudes in plural societies. Applied Psychology: An International Review, 38(2), 185-206. doi: 10.1111/j.1464-0597.1989.tb01208.x

Berry, J. W., Phinney, J. S., Sam, D. L., \& Vedder, P. (2006). Immigrant youth: Acculturation, identity, and adaptation. Applied Psychology-an International Review-Psychologie Appliquee-Revue Internationale, 55(3), 303-332. doi:10.1111/j.14640597.2006.00256.x

Berry, J.W. (1997). Immigration, Acculturation, and Adaptation. APPL psychol-int REV, 46 (1),21-32. doi:10.1111 / j.1464-0597.1997. Tb01087.x

Berry, J.W. (2001). A psychology of immigration. Journal of Social Issues, 57(3), 615-631. doi: $10.1111 / 0022-4537.00231$

Bigagli, F. (2019). School, ethnicity and nation-building in post-colonial Myanmar. Research in Educational Policy and Management, 1(1), 1-16. doi:10.46303/repam.01.01.1

Birman, D., \& Trickett, E. J. (2001). Cultural transitions in first-generation immigrants Acculturation of soviet Jewish refugee adolescents and parents. Journal of CrossCultural Psychology, 32(4), 456-477. doi:10.1177/0022022101032004006

Brown, C. S., \& Chu, H. (2012). Discrimination, Ethnic Identity, and Academic Outcomes of Mexican Immigrant Children: The Importance of School Context. Child Development, 83(5), 1477-1485. doi:10.1111/j.1467-8624.2012.01786.x

Chen, C., \& Leydesdorff, L. (2014). Patterns of connections and movements in dual-map overlays: A new method of publication portfolio analysis. Journal of the Association for Information Science and Technology, 65(2), 334-351. doi: 10.1002/asi.22968.

Chen, C., Ibekwe-SanJuan, F., \& Hou, J. (2010). The structure and dynamics of co-citation clusters: A multiple-perspective co-citation analysis. Journal of the American Society for Information Science and Technology, 61(7), 1386-1409. doi: 10.1002/asi.21309.

Chung, N., Koo,C.(2015). The use of social media in travel information search. Telematics and Iformatics, 32: 215-229. doi.org/10.1016/j.tele.2014.08.005

Ferrari, L., Manzi, C., Benet-Martinez, V., \& Rosnati, R. (2019). Social and Family Factors Related to Intercountry Adoptees and Immigrants' Bicultural Identity Integration. Journal of Cross-Cultural Psychology, 50(6), 789-805. doi:10.1177/0022022119850339

Gurer, C. (2019). Refugee Perspectives on Integration in Germany. American Journal of Qualitative Research, 3(2), 52-70. doi:10.29333/ajqr/6433

Halpern, C. (2018). Multicultural for who? A review of a comprehensive multicultural textbook. Journal of Culture and Values in Education, 1(2), 58-62. doi:10.46303/jcve.01.02.4

Huang, L., Shi, X., Zhang, N., Gao, Y., Bai, Q., Liu, L., . . . Hong, B. (2020). Bibliometric analysis of trends and issues in traditional medicine for stroke research: 2004-2018. BMC complementary medicine and therapies, 20(1), 39-39. doi:10.1186/s12906-0202832-x

Hunt, G., Kolind, T., \& Antin, T. (2018). Conceptualizing ethnicity in alcohol and drug research: Epidemiology meets social theory. Journal of Ethnicity in Substance Abuse, 17(2), $187-$ 198. doi:10.1080/15332640.2017.1316223

Huynh, Q. L., Benet-Martinez, V., \& Nguyen, A. M. D. (2018). Measuring Variations in Bicultural Identity Across US Ethnic and Generational Groups: Development and Validation of the Bicultural Identity Integration Scale-Version 2 (BIIS-2). Psychological 
Assessment, 30(12), 1581-1596. doi:10.1037/pas0000606

Kvernmo, S., \& Heyerdahl, S. (2004). Ethnic identity and acculturation attitudes among indigenous Norwegian Sami and ethnocultural Kven adolescents. Journal of Adolescent Research, 19(5), 512-532. doi:10.1177/0743558403259991

Kwan, K.L.K..,\&Sodowsky,G..R. (1997). Internal and external ethnic identity and theircorrelates: a study of Chinese American immigrants. Journal of Multicultural Counseling\&Development, 25(1), 51-67. doi.org/10.1002/j.2161-1912.1997.tb00315.x

LaFromboise, T., Coleman, H. L. K., \& Gerton, J. (1993). Psychological Impact of Biculturalism:Evidence and Theory. Psychological Bulletin, 114(3), 395-412. doi:10.1037/0033-2909.114.3.395

Laroche, M., Kim,C.\&Hui, M.K.. (1997). A comparative investigation of dimensional structures of acculturation for Italian Canadians and Greek Canadians. The Journal of Social Psychology 137(3), 317-33. doi: 10.1080/00224549709595443

Lee, R. M. (2005). Resilience against discrimination: Ethnic identity and other-group orientation as protective factors for Korean Americans. Journal of Counseling Psychology, 52(1), 36-44. doi:10.1037/0022-0167.52.1.36

Lee, T. K., Meca, A., Unger, J. B., Zamboanga, B. L., Baezconde-Garbanati, L., GonzalesBacken, M., . . S Schwartz, S. J. (2020). Dynamic Transition Patterns in Acculturation Among Hispanic Adolescents. Child Development, 91(1), 78-95. doi:10.1111/cdev.13148

Lewis, J. A., Raque-Bogdan, T. L., Lee, S., \& Rao, M. A. (2018). Examining the Role of Ethnic Identity and Meaning in Life on Career Decision-Making Self-Efficacy. Journal of Career Development, 45(1), 68-82. doi:10.1177/0894845317696803

Meca, A., Cobb, C., Xie, D., Schwartz, S. J., Allen, C., \& Hunter, R. (2017). Exploring Adaptive Acculturation Approaches Among Undocumented Latinos: A Test of Berry's Model. Counseling Psychologist, 45(8), 1115-1140. doi:10.1177/0011000017745978

Mitra, A., \& Evansluong, Q. (2019). Narratives of integration: Liminality in migrant acculturation through social media. Technological Forecasting and Social Change, 145, 474-480. doi:10.1016/j.techfore.2019.01.011

Motti-Stefanidi, F., Berry, J., Chryssochoou, X., Lackland Sam, D., \& Phinney, J. (2012). Positive Immigrant Youth Adaptation in Context. Realizing the Potential of Immigrant Youth, 117-158. doi:10.1017/cbo9781139094696.008

Nguyen, A. M. D., \& Benet-Martinez, V. (2013). Biculturalism and Adjustment: A MetaAnalysis. Journal of Cross-Cultural Psychology, 44(1), 122-159. doi:10.1177/0022022111435097

Peng, R.-Z., Zhu, C., \& Wu, W.-P. (2020). Visualizing the knowledge domain of intercultural competence research: A bibliometric analysis. International Journal of Intercultural Relations, 74, 58-68. doi:10.1016/j.ijintrel.2019.10.008

Phinney, J. S. (1992). The Multigroup Ethnic Identity Measure. J ADOLESCENT RES, V7. doi $10.1177 / 074355489272003$

Phinney, J. S. (2003). Ethic identity and acculturation. Acculturation: Advances in Theory, Measurement, and Applied Research., 63-81. doi:10.1037/10472-006

Phinney, J. S., Horenczyk, G., Liebkind, K., \& Vedder, P. (2001). Ethnic identity, immigration, and well-being: An interactional perspective. Journal of Social Issues, 57(3), 493-510. doi:10.1111/0022-4537.00225

Phinney, J. S., Jacoby, B., \& Silva, C. (2007). Positive intergroup attitudes: The role of ethnic identity. International Journal of Behavioral Development, 31(5), 478-490. doi:10.1177/0165025407081466

Phinney, J. S., Ong, A., \& Madden, T. (2000). Cultural values and intergenerational value discrepancies in immigrant and non-immigrant families. Child Development, 71(2), 
528-539. doi:10.1111/1467-8624.00162

Phinney, J. S., Romero, I., Nava, M., \& Huang, D. (2001). The role of language, parents, and peers in ethnic identity among adolescents in immigrant families. Journal of Youth and Adolescence, 30(2), 135-153. doi:10.1023/a:1010389607319

Ratini, T. (2019). Refugee. American Journal of Qualitative Research, 3(2), 9799. doi:10.29333/ajqr/6432

Rivas-Drake, D., Seaton, E. K., Markstrom, C., Quintana, S., Syed, M., Lee, R. M., . . Racial Identity in the 21st Century Study, G. (2014). Ethnic and racial identity in adolescence: implications for psychosocial, academic, and health outcomes. Child Development, 85(1), 40-57. doi:10.1111/cdev.12200

Rivas-Drake, D., Syed, M., Umaña-Taylor, A., Markstrom, C., French, S., ... Schwartz, S. J. (2014). Feeling Good, Happy, and Proud: A Meta-Analysis of Positive Ethnic-Racial Affect and Adjustment. Child Development, 85(1), 77-102. doi:10.1111/cdev.12175

Ryder, A. G., Alden, L. E., \& Paulhus, D. L. (2000). Is acculturation unidimensional or bidimensional? A head-to-head comparison in the prediction of personality, self-identity, and adjustment. Journal of Personality and Social Psychology, 79(1), 49-65. doi:10.1037//0022-3514.79.1.49

Sam, D. L., \& Berry, J. W. (2010). Acculturation. Perspectives on Psychological Science, 5(4), 472-481. doi:10.1177/1745691610373075

Schotte, K., Stanat, P., \& Edele, A. (2018). Is Integration Always most Adaptive? The Role of Cultural Identity in Academic Achievement and in Psychological Adaptation of Immigrant Students in Germany. Journal of Youth and Adolescence, 47(1), 16-37. doi:10.1007/s 10964-017-0737-x

Schwartz, S. J., Montgomery, M. J., \& Briones, E. (2006). The role of identity in acculturation among immigrant people: Theoretical propositions, empirical questions, and applied recommendations. Human Development, 49(1), 1-30. doi:10.1159/000090300

Schwartz, S. J., Unger, J. B., Rosiers, S. E. D., Huang, S., Baezconde-Garbanati, L., LorenzoBlanco, E. I., . . . Szapocznik, J. (2012). Substance use and sexual behavior among recent Hispanic immigrant adolescents: Effects of parent-adolescent differential acculturation and communication. Drug and Alcohol Dependence, 125, S26-S34. doi:10.1016/j.drugalcdep.2012.05.020

Schwartz, S. J., Unger, J. B., Zamboanga, B. L., \& Szapocznik, J. (2010). Rethinking the Concept of Acculturation Implications for Theory and Research. American Psychologist, 65(4), 237-251. doi:10.1037/a0019330

Schwartz, S. J., Zamboanga, B. L., \& Jarvis, L. H. (2007). Ethnic Identity and Acculturation in Hispanic Early Adolescents: Mediated Relationships to Academic Grades, Prosocial Behaviors, and Externalizing Symptoms. Cultural Diversity \& Ethnic Minority Psychology, 13(4), 364-373. doi:10.1037/1099-9809.13.4.364

Smith, T. B., \& Silva, L. (2011). Ethnic identity and personal well-being of people of color: A meta-analysis. Journal of Counseling Psychology, 58(1), 42-60. doi: 10.1037/a0021528

Soyer, G. (2019). Urie Bronfenbrenner: The Ecology of Human Development Book Review. Journal of Culture and Values in Education, 2(2), 77-80. doi:10.46303/jcve.02.02.6

Tao, L., Zhou, S., Tao, Z., Wen, K., Da, W., Meng, Y., \& Zhu, Y. (2020). The publication trends and hot spots of scoliosis research from 2009 to 2018: a 10-year bibliometric analysis. Annals of Translational Medicine, 8(6). doi:10.21037/atm.2020.02.67

Teppang, N., Han, M., \& Lee, Y. (2019). Exploring ethnic identity and its development process among young adult Filipino Americans. Journal of Ethnic \& Cultural Diversity in Social Work, 28(4), 408-423. doi:10.1080/15313204.2017.1409679

Umana-Taylor, A. J., Quintana, S. M., Lee, R. M., Cross, W. E., Jr., Rivas-Drake, D., Schwartz, S. J., . . Racial Identity in the 21 st Century Study, G. (2014). Ethnic and racial identity 
during adolescence and into young adulthood: an integrated conceptualization. Child Development, 85(1), 21-39. doi:10.1111/cdev.12196

Ward, C., \& Geeraert, n. (2016). Advancing acculturation and found the and research: the acculturation process in its ecological context. Curr Opin Psychol, 8, 98-104. doi: 10.1016 / j.carol carroll opsyc 2015.09.021

Ward, C., \& Kus, 1. (2012). Back to and beyond Berry's basics:The conceptualization, operationalization and classification of acculturation. Interethnic Journal of Intercultural Relations, 36 (4), 472-485. doi: 10.1016 / j.i jintrel. 2012.02.002

Wu, M., Wang, Y., Yan, C., \& Zhao, Y. (2020). Study on subclinical hypothyroidism in pregnancy: a bibliometric analysis via CiteSpace. Journal of Maternal-Fetal \& Neonatal Medicine. doi:10.1080/14767058.2020.1729731

Wu, Y. J., Outley, C., \& Matarrita-Cascante, D. (2019). Cultural Immersion Camps and Development of Ethnic Identity in Asian American Youth. Journal of Youth Development, 14(2), 166-182. doi:10.5195/jyd.2019.708

Yoon, E., Chang, C. T., Kim, S., Clawson, A., Cleary, S. E., Hansen, M., . . Gomes, A. M. (2013). A Meta-Analysis of Acculturation/Enculturation and Mental Health. Journal of Counseling Psychology, 60(1), 15-30. doi:10.1037/a0030652

Zhang, S. Y., Verkuyten, M., \& Weesie, J. (2018). Dual identity and psychological adjustment: A study among immigrant-origin members. Journal of Research in Personality, 74, 6677. doi:10.1016/j.jrp.2018.02.008

\section{Notes on Contributors}

Yuan Shuangyun is a Ph.D student at Rajamangala University of Technology Rattanakosin in Thailand. Her research interests focus on mutual acculturation of ethnic minorities and majorities, multiple identities, ethnic identity, and intergenerational transmission of values and traditional culture in the information society.

Li Hongxia is a doctoral supervisor at Rajamangala University of Technology Rattanakosin in Thailand and a professor of Chongqing Technology and Business University in China. Her research interests focus on information management, management psychology and behavior, management science, operation management, information system, and information security. 